\title{
Influenza virus and endothelial cells: a species specific relationship
}

\author{
Kirsty R. Shortt ${ }^{1,2}$, Edwin J. B. Veldhuis Kroeze ${ }^{1}$, Leslie A. Reperant ${ }^{1}$, Mathilde Richard ${ }^{1}$ and \\ Thijs Kuiken ${ }^{1 *}$
}

${ }^{1}$ Department of Viroscience, Erasmus Medical Centre, Rotterdam, Netherlands

2 School of Biomedical Sciences, University of Queensland, Brisbane, QLD, Australia

\section{Edited by:}

Dale L. Barnard, Utah State

University, USA

Reviewed by:

Daniel C. Pevear, VenatoRx

Pharmaceuticals Incorporated, USA

Nejat Duzgunes, University of the

Pacific School of Dentistry, USA

Peirong Jiao, South China

Agricultural University, China

*Correspondence:

Thijs Kuiken, Department of Viroscience, Erasmus Medical

Centre, Dr. Molewaterplein 50 ,

3015GE Rotterdam, Netherlands

e-mail: t.kuiken@erasmusmc.nl
Influenza A virus (IAV) infection is an important cause of respiratory disease in humans. The original reservoirs of IAV are wild waterfowl and shorebirds, where virus infection causes limited, if any, disease. Both in humans and in wild waterbirds, epithelial cells are the main target of infection. However, influenza virus can spread from wild bird species to terrestrial poultry. Here, the virus can evolve into highly pathogenic avian influenza (HPAl). Part of this evolution involves increased viral tropism for endothelial cells. HPAI virus infections not only cause severe disease in chickens and other terrestrial poultry species but can also spread to humans and back to wild bird populations. Here, we review the role of the endothelium in the pathogenesis of influenza virus infection in wild birds, terrestrial poultry and humans with a particular focus on HPAI viruses. We demonstrate that whilst the endothelium is an important target of virus infection in terrestrial poultry and some wild bird species, in humans the endothelium is more important in controlling the local inflammatory milieu. Thus, the endothelium plays an important, but species-specific, role in the pathogenesis of influenza virus infection.

\section{INTRODUCTION}

Influenza A virus (IAV) is a negative-sense RNA virus of the Family Orthomyxoviridae. IAVs can be classified into different subtypes based on antigenic differences in the two surface glycoproteins of the virus, the hemagglutinin (HA) and neuraminidase (NA). Each year, antigenic changes (or "drift") in the HA and NA result in a seasonal outbreak of IAV in the human population. However, when there is a dramatic change in the HA and/or $\mathrm{NA}$, often originating from the avian reservoir, global pandemics can result. In the last 100 years there have been four IAV pandemics in the human population: the $1918 \mathrm{H} 1 \mathrm{~N} 1$ pandemic, the $1957 \mathrm{H} 2 \mathrm{~N} 2$ pandemic, the $1968 \mathrm{H} 3 \mathrm{~N} 2$ pandemic and the 2009 H1N1 pandemic. These pandemics have all caused significant morbidity and mortality. Indeed, the $1918 \mathrm{H} 1 \mathrm{~N} 1$ virus was so severe that life expectancy in the U.S.A. dropped by 11.8 years from 1917 to 1918 (Noymer and Garenne, 2000). The constant threat of a future IAV pandemic highlights the need to study and understand IAV pathogenesis not only in humans, but also in the virus' natural avian reservoirs. The original reservoirs of IAV are wild waterfowl (order Anseriformes-which includes geese, ducks, and swans) and shorebirds (order Charadriiformeswhich includes gulls and waders). Sixteen different HA subtypes and 9 different NA subtypes of IAV have been recorded in wild waterfowl. A subset of these different IAV strains can then spread from wild bird populations to terrestrial poultry (order Galliformes). Here, IAV can cause a mild or subclinical infection of the respiratory and/or gastrointestinal tract, and is thus referred to as a low pathogenic avian influenza (LPAI) virus. LPAI viruses of the $\mathrm{H} 5$ and $\mathrm{H} 7$ subtypes can subsequently evolve in poultry to become highly pathogenic avian influenza (HPAI) viruses, which typically cause a fatal and systemic infection. LPAI and HPAI viruses can cause respiratory infection in humans, with HPAI viruses occasionally reported in extra-respiratory organs.

The pathogenesis of IAV infection differs markedly between wild waterbirds, terrestrial poultry and humans. In all three host groups, endothelial cells play a key role in disease pathogenesiseither as the primary cellular target of viral infection or as orchestrators of the anti-viral immune response. Here, we review the currently available literature on the role of the endothelium in the pathogenesis of IAV (in particular HPAI H5N1 viruses) in terrestrial poultry, wild birds and humans. Specifically, we will compare the ability of IAV to infect and/or "activate" the endothelium across these different host groups.

\section{TERRESTRIAL POULTRY (ORDER GALLIFORMES)}

Typically, terrestrial poultry infected with LPAI viruses display limited clinical signs and with no evidence of endothelial cell infection (rather the virus preferentially infects epithelial cells of the respiratory tract) (Hooper and Selleck, 2003). However, viruses of the $\mathrm{H} 5$ and $\mathrm{H} 7$ subtype can evolve in terrestrial poultry to become HPAI. This evolution typically occurs via the addition of a multi-basic cleavage site in the viral HA. This then allows the HA to be cleaved (a prerequisite for viral infection) by the 
ubiquitously present furin family of enzymes. In contrast, LPAI can only be cleaved by trypsin like enzymes that are present within the respiratory and digestive tract. Upon evolution to HPAI, the cell tropism of IAV changes dramatically. Studies on naturally or experimentally infected chickens show that HPAI can infect the endothelium in a variety of different organs including, but not limited to, the lung, heart, brain, and spleen (Brown et al., 1992; Suarez et al., 1998; Ito et al., 2002; Jones and Swayne, 2004; Nakatani et al., 2005; Muramoto et al., 2006; Swayne, 2007; Nakamura et al., 2008; van Riel et al., 2009; Wibawa et al., 2013) (see Figure 1). This endothelial cell tropism can be so striking that in chickens infected with H5N1, IAV antigen is more prevalent in the endothelial cells of the respiratory and intestinal tract than in the epithelial cells of the same tissues (Wibawa et al., 2013). Similarly, in Galliformes other than chickens viral antigens are predominant in the vascular and capillary endothelial cells of various tissues including the lung, liver, brain, skeletal muscle, pancreas, heart, kidney, spleen, and bursa (Perkins and Swayne, 2001, 2003; Lee et al., 2005; Bertran et al., 2011, 2013). The endothelial tropism of HPAI viruses is determined, at least in part, by the presence of the multi-basic cleavage site in the HA, as the removal of these basic amino acid residues reduces endothelial tropism (Schat et al., 2012). The polarity of virus budding may also contribute this distinct pattern of viral infection (Feldmann et al., 2000).

The endothelial tropism of HPAI viruses in chickens and other Galliformes has important pathological ramifications. Firstly, IAV infection of chicken endothelial cells is associated with the apoptotic death of these cells (Ito et al., 2002). The loss of endothelial cells is likely to contribute to the oedema and hemorrhaging observed in the wattle, comb, lungs and legs of chickens infected with HPAI viruses (Perkins and Swayne, 2002a; van Riel et al., 2009). A loss of endothelial cells can also detrimentally affect blood coagulation (Muramoto et al., 2006; Swayne, 2007). Damage to endothelial cells activates the extrinsic coagulation cascade and facilitates the microthrombosis. This can then lead to disseminated intravascular coagulation (DIC) whereby the coagulation cascade become "hyper-activated," resulting in thrombocytopenia, wide-spread hemorrhaging and ischaemia. Consistent with a role for DIC in the pathogenesis of HPAI viruses in chickens, Muramoto and colleagues demonstrated that chickens intravenously infected with $\mathrm{H} 5 \mathrm{~N} 1$ display both microthrombosis and thrombocytopenia (Muramoto et al., 2006). Similarly, chickens infected intranasally with $\mathrm{H} 5 \mathrm{~N} 1$ display microthrombosis in the lung within $24 \mathrm{~h}$ post-infection. It has also been suggested that the replication of HPAI viruses in endothelial cells could disrupt the innate immune response (Suzuki et al., 2009), thermoregulation (Suzuki et al., 2009) and facilitate the systemic spread of the virus to parenchymal cells of the brain, skin, and visceral organs (Pantin-Jackwood and Swayne, 2009). Together, these features help account for the rapid and high mortality rates of HPAI in Galliformes. For example, in chickens death typically occurs within 2 days post-infection, often in the absence of visible clinical signs (Wibawa et al., 2013). Similarly, during an outbreak of a HPAI H7N1 virus in Italy, turkeys and guinea fowl (reared on litter) had a $100 \%$ mortality rate within a mere $48-72 \mathrm{~h}$ of becoming symptomatic (Mutinelli et al., 2003).
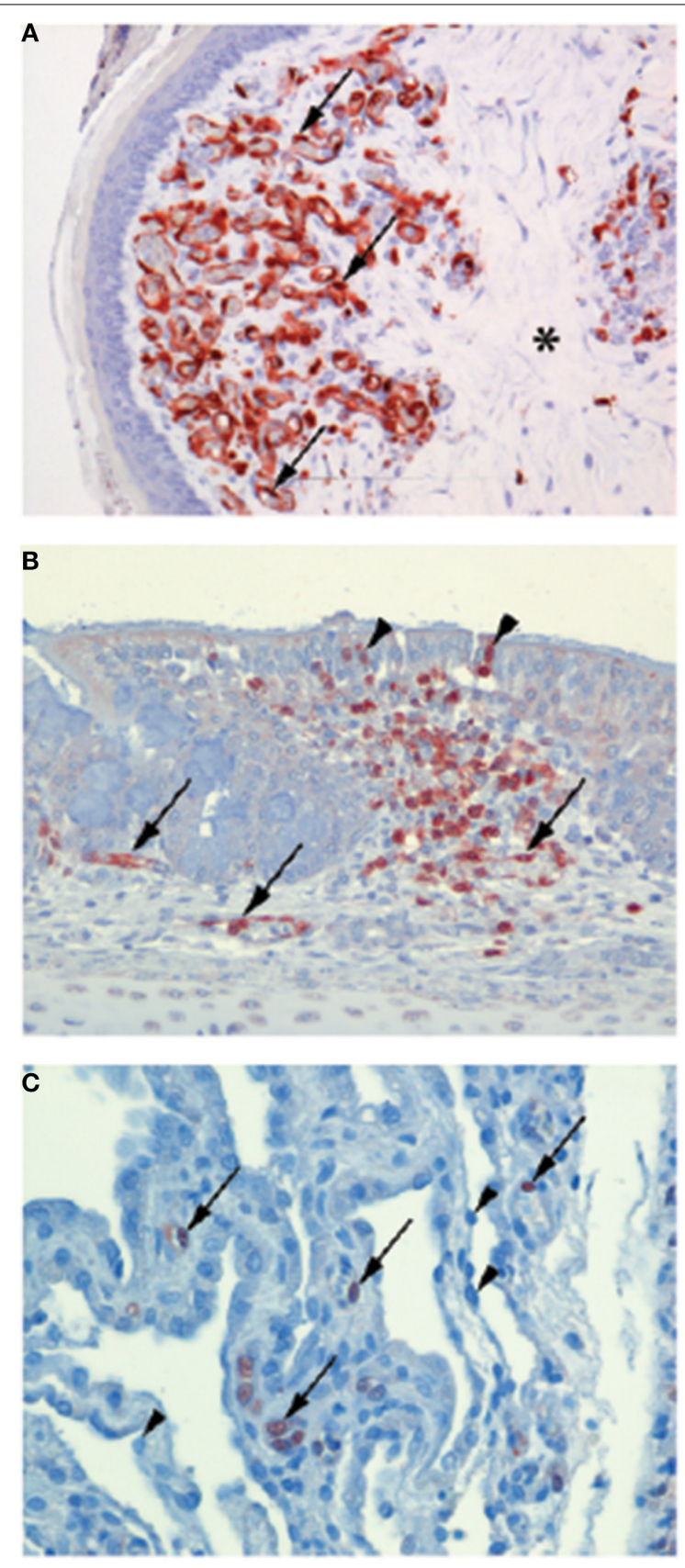

FIGURE 1 | Endotheliotropism and epitheliotropism of IAVs in chickens. Virus distribution in: (A) endothelial cells of the wattle of a chicken naturally infected with HPAI H7N7 virus. Brown-reddish staining antigen indicative of viral replication is present in many endothelial cell nuclei (arrows) and cytoplasm lining the small blood vessels. The dermis is expanded by edema (asterisk). (original magnification 200x, in van Riel et al. (2009) (B) Epithelial cell nuclei (arrowheads) and in endothelial cells (arrows) of the nasal mucosa of a chicken $24 \mathrm{~h}$ after experimental intranasal infection with $10^{5} \mathrm{TCID}_{50}$ of HPAI H5N1 virus A/Indonesia/05/2005, illustrating both epitheliotropism and endotheliotropism of the virus (original magnification $200 \times$ ). (C) Endothelial cell nuclei (arrows) of the lung interstitium $24 \mathrm{~h}$ after infection of the same chicken as in (B), the alveolar lining epithelial cells nuclei (arrowheads) do not stain positive for viral antigen (original magnification 400x). (Immunohistochemistry (IHC) for IAV-nucleoprotein (NP) with hematoxylin counterstain). 


\section{WILD BIRDS (ORDER ANSERIFORMES AND CHARADRIIFORMES)}

In wild birds, LPAI viruses normally present as a sub-clinical infection with little involvement of the endothelium in disease pathogenesis (Webster et al., 1992; Pantin-Jackwood and Swayne, 2009). Prior to the emergence of HPAI H5N1 viruses, there was only one recorded incidence of a HPAI strain being detected in wild birds (Becker, 1966). It was therefore assumed that HPAI strains were unlikely to transmit back to the wild bird population and cause disease following their emergence in poultry. However, since 2002 the HPAI H5N1 strain has caused infection and mortality in a variety of wild birds. Unlike LPAI viruses, $\mathrm{H} 5 \mathrm{~N} 1$ viruses in wild birds do not infect intestinal epithelial cells. Instead, the virus predominantly infects cells in the respiratory tract and other organs (see Tables 1, 2) and infection can be associated with severe necrosis and inflammation (Kwon et al., 2005; Pasick et al., 2007; Bröjer et al., 2009; Daoust et al., 2011; Wibawa et al., 2013). H5N1 viruses display, at most, limited tropism for the endothelium in wild birds (see Tables 1, 2 ), and it is therefore unlikely that endothelial cell infection plays a major role in disease pathogenesis. However, one notable exception to this trend is black swans (Brown et al., 2008a). Upon infection with A/whooper swan/Mongolia/244/05(H5N1), $100 \%(n=5)$ of black swans succumbed to disease within $2-3$ days (as seen during H5N1 infection of chickens, this was often observed in the absence of clinical signs of disease) (Brown et al., 2008a). Immunohistochemistry showed that the endothelial cells throughout the body were the primary target of IAV infection, and the presence of IAV antigen was associated with multiorgan necrosis and mild acute inflammation (Brown et al., 2008a). Although a tropism for the endothelium is observed in other species of swans, this does not appear to be as pronounced as that seen in the black swan (Ellis et al., 2004; Teifke et al., 2007; Brown et al., 2008a; Kalthoff et al., 2008; Kwon et al., 2010). For example, viral antigen was detected infrequently or not at all in the endothelial cells of whooper swans (Teifke et al., 2007; Brown et al., 2008a) and trumpeter swans (Brown et al., 2008a) following either a natural or experimental infection with H5N1. Similarly, whilst endothelial cells of mute swans were positive for IAV, and widespread hemorrhage was recorded, this was only detected in 3 out of 12 birds (Kalthoff et al., 2008). Thus, although the ability of HPAI H5N1 to infect endothelial cells contributes to the severity of the disease observed in black swans this does not necessarily hold true for other species of swans or wild birds.

\section{HUMANS}

In humans, the primary cellular targets of IAV are epithelial cells in the respiratory tract. Seasonal IAVs, which are adapted to and circulate in the human population, typically infect ciliated cells in the upper respiratory tract, trachea and bronchi (van Riel et al., 2007b, 2010). In contrast, HPAI viruses such as H5N1 preferentially infect the lower respiratory tract, specifically club cells and alveolar type II pneumocytes (van Riel et al., 2006, 2007a). This differential tropism reflects, in part, the ability of $\mathrm{H} 5 \mathrm{~N} 1$ viruses to bind to $\alpha$-2,3-linked sialosaccharides (expressed on type II pneumocytes) whilst seasonal IAVs typically display a preference for $\alpha$-2,6-linked sialic acid (Shinya et al., 2006; van Riel et al., 2006, 2007a). Within the lower respiratory tract, alveolar epithelial cells are in close proximity to the underlying endothelium. Indeed, in the human alveolus there is on average only $0.5 \mu \mathrm{m}$ separating the airspace from the capillary (Piantadosi and Schwartz, 2004). During IAV infection the endothelium is therefore likely to be exposed to free virus particles produced by infected and damaged epithelial cells. It is often suggested that-like chickens and black swans-IAV infects human endothelial cells, and that this contributes to disease pathogenesis (Chan et al., 2009; Ocaña-Macchi et al., 2009; Armstrong et al., 2012, 2013; Zeng et al., 2012). For example, in vitro studies using primary human lung microvascular endothelial cells demonstrated that endothelial cells can be infected by seasonal H3N2 IAV, with infection ultimately resulting in increased endothelial cell permeability (Armstrong et al., 2012). Others have suggested that IAV infection of the pulmonary endothelium is a unique feature of infection with $\mathrm{H} 5 \mathrm{~N} 1$ viruses, as $\mathrm{H} 5 \mathrm{~N} 1$ strains are able to efficiently infect and replicate in human microvascular endothelial cells whereas other IAV strains do not (Chan et al., 2009; Ocaña-Macchi et al., 2009; Zeng et al., 2012). However, in spite of these in vitro studies, there is limited evidence suggesting that IAV infection of human endothelial cells occurs in vivo. Post mortem analysis of patients who succumbed to $\mathrm{H} 5 \mathrm{~N} 1$ did not demonstrate the presence of virus in pulmonary endothelial cells (Gu et al., 2007). Similarly, endothelial cells were only very infrequently infected in a limited number of patients infected with fatal pandemic $2009 \mathrm{H} 1 \mathrm{~N} 1$ (Shieh et al., 2010). Whilst one recent study in mice recorded endothelial cell infection (Ogiwara et al., 2014), in most animal models of human infection IAV infection of the endothelium is rarely observed (Kuiken et al., 2010) (see Figure 2). Together, these data suggest that infection of endothelial cells by IAV is unlikely to contribute to disease severity in humans.

Although human endothelial cells are not infected by IAV in vivo, endothelial cells may still play an important role in the pathogenesis of IAV in humans. During IAV infection pulmonary endothelial cells are thought to be the most important source of cytokines in the lung (Teijaro et al., 2011). Specifically, in a mouse model of influenza, treatment with a SIP1 receptor agonist reduced IAV-induced mortality by blocking endothelial cell cytokine and chemokine production (Teijaro et al., 2011), suggesting a key role for endothelial cells in IAV pathogenesis. It has also been shown that the IAV-induced inflammatory response (namely the production of TNF $\alpha$, IL- 6 and IL-1 $\beta$ ) upregulates trypsin production (Wang et al., 2010). The increased amount of trypsin then damages the tight junction protein zona-occludens 1 that is found between endothelial cells and increases endothelial permeability (Wang et al., 2010). However, it is important to note that this is unlikely to account for the pulmonary oedema observed during severe IAV infection as it is epithelial, not endothelial, cells that play the most important role in ensuring that the alveolus remains free of fluid (Gorin and Stewart, 1979). Pro-inflammatory cytokines, derived either from the endothelium or other cells in the lung, may also contribute to the development of thrombosis during IAV infection (Babinska et al., 2002; Armstrong et al., 2013). For example, treatment of human umbilical vein endothelial cells with TNF $\alpha$ significantly increased platelet binding to the cells by promoting 


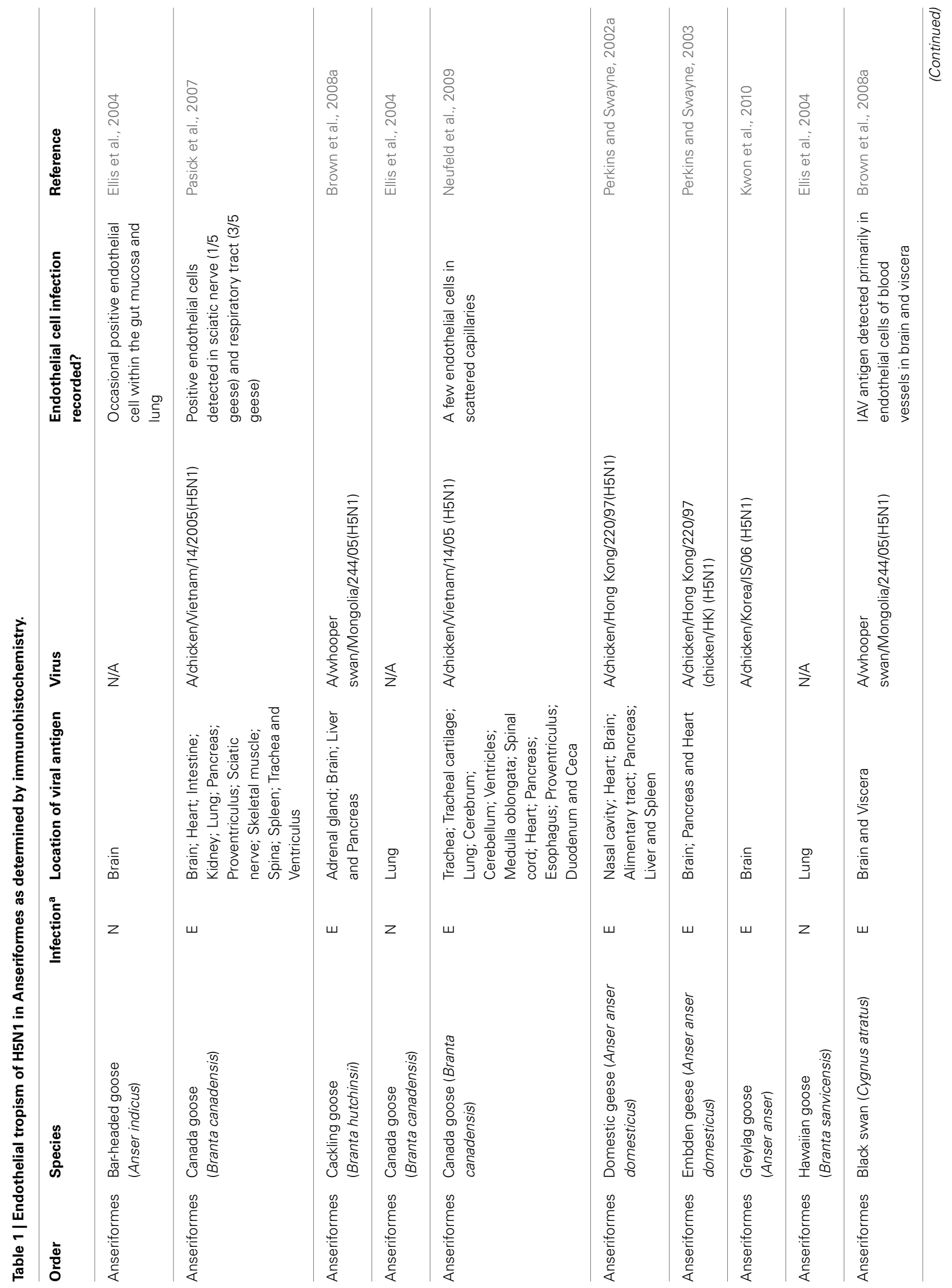




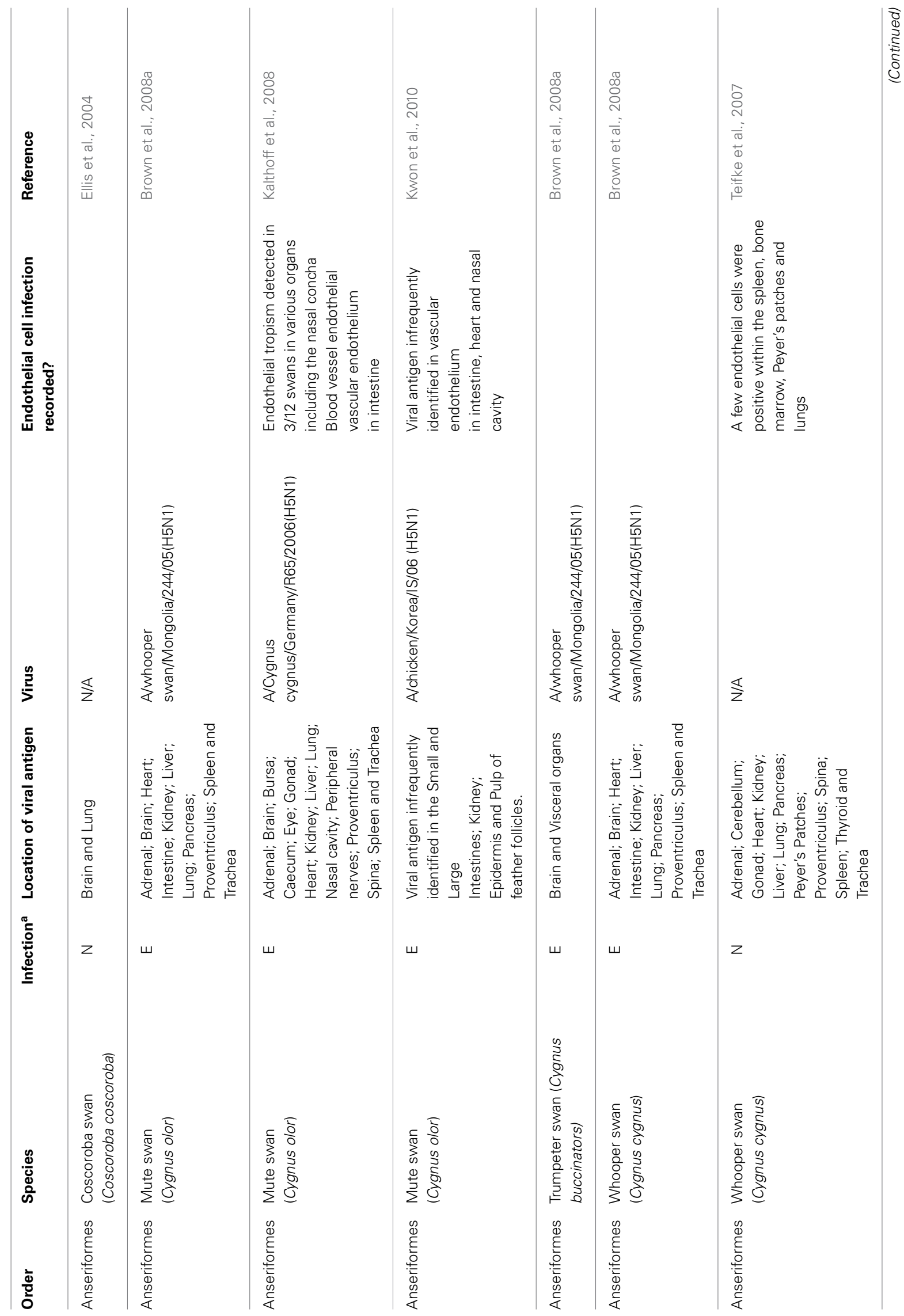




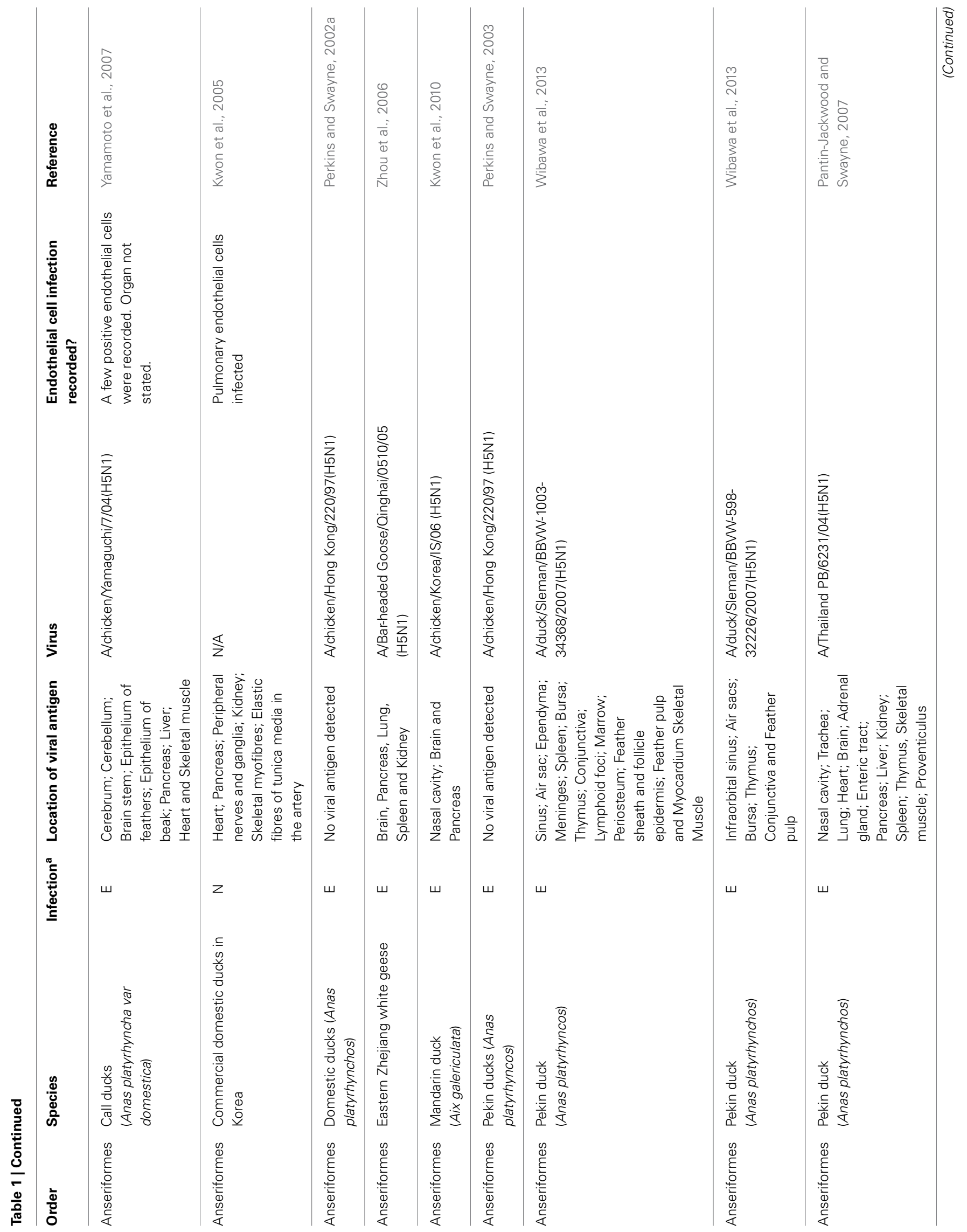




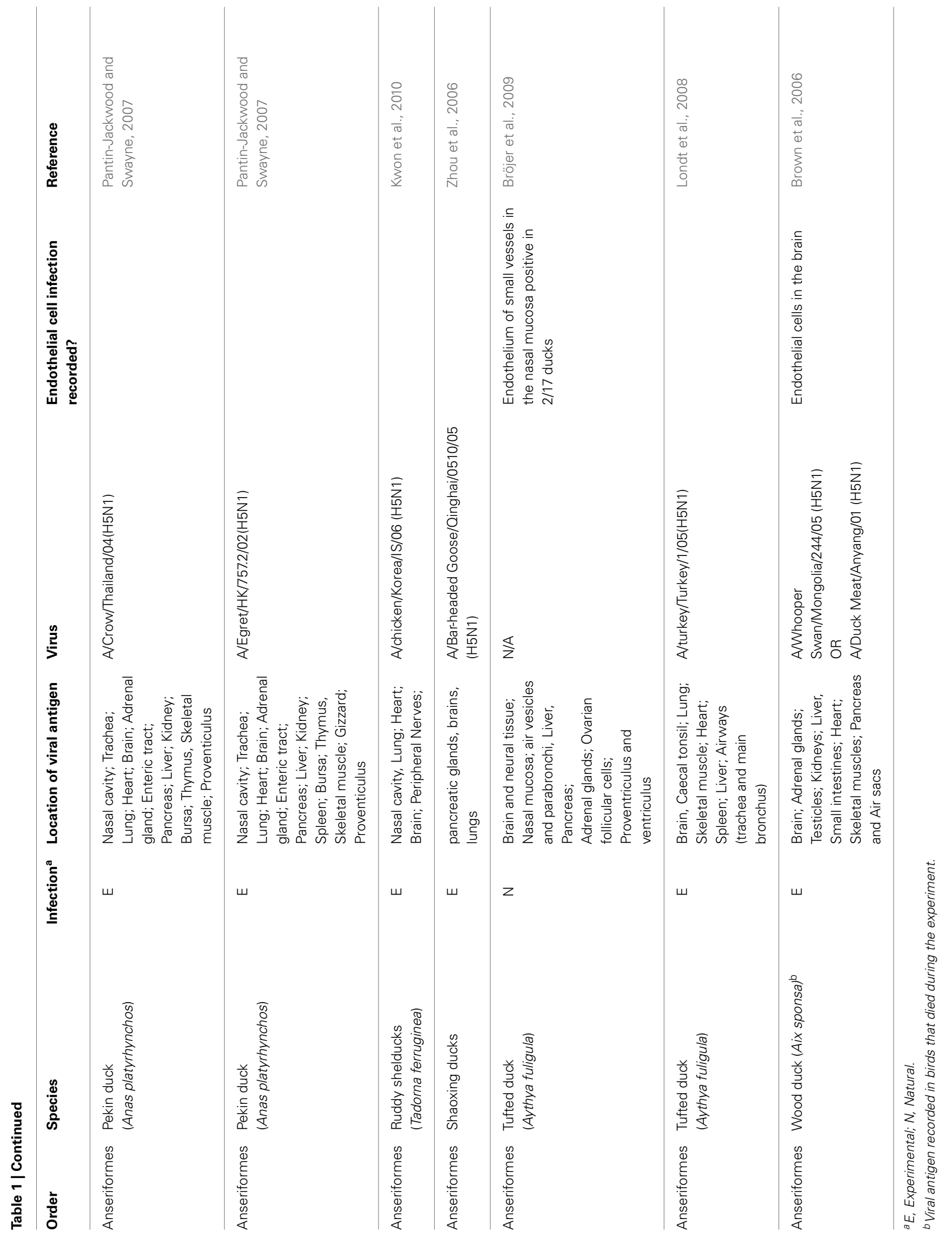




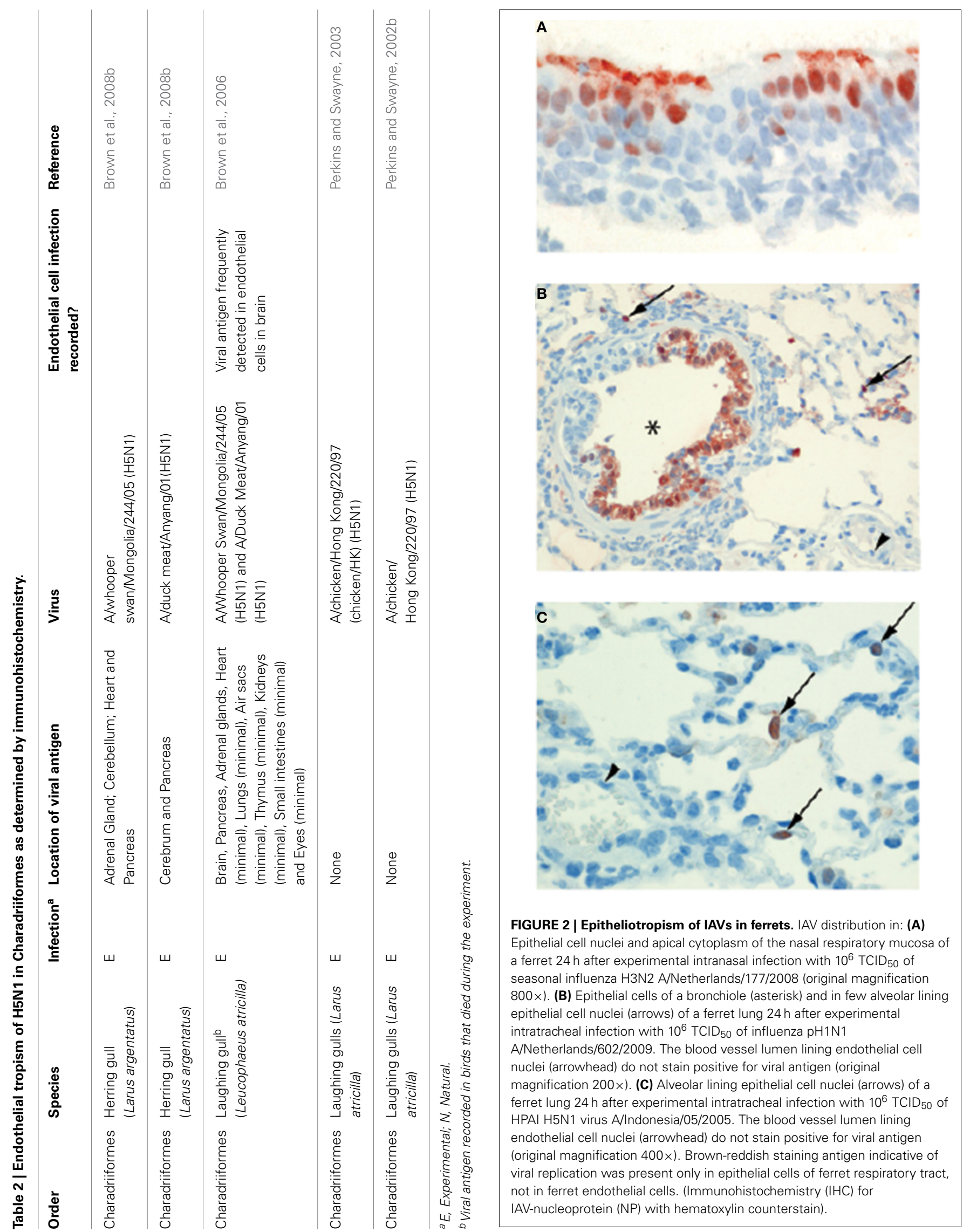




\section{Endothelial cell infection in cats.}

Upon the initial emergence of $\mathrm{H} 5 \mathrm{~N} 1$ viruses, mortality in cats was observed in areas where the viruses were spreading in wild and domestic birds. This suggested that cats were susceptible to infection. This was unusual as cats have long been considered to be refractory to IAV infection. H5N1 viruses administered to cats intratracheally resulted in productive infection of many organs, including the respiratory tract, with parenchymal and epithelial cells as the primary targets for viral replication (Rimmelzwaan et al., 2006). These studies demonstrated that domestic cats could indeed develop clinical disease upon H5N1 infection. Cats and other carnivores can be exposed to H5N1 viruses by feeding on sick or dead birds. In order to mimic this route of infection, Reperant and colleagues (2012) administered H5N1 to the small intestine of cats using enteric-coated capsules (the use of which avoided accidently exposing the respiratory tract to the inoculum). Three days post-infection $\mathrm{H} 5 \mathrm{~N} 1$ infected cats became lethargic and began to display severe clinical signs. Surprisingly, immunohistochemistry demonstrated that there was an overwhelming infection of endothelial cells in virtually every organ of infected cats, in a pattern reminiscent of that observed in chickens. In contrast, parenchymal cells were rarely infected. In particular, infection of respiratory epithelial cells was not observed, despite massive infection of the pulmonary endothelium. The virus used to infect the cats via the intestine had been isolated from the liver of infected chickens, and may have accumulated mutations potentially responsible for such difference in tissue tropism. However, analyses of the viruses used to infect, and recovered from, cats inoculated intra-tracheally and via the intestine, revealed no coding differences associated with the difference in tropism. These data suggest that the route of virus exposure may influence the role of the endothelium in the pathogenesis of influenza virus in mammals.

the interaction between the F11 receptor on platelets and the F11 receptor on endothelial cells (Babinska et al., 2002). This observation is supported by epidemiological evidence from the $2009 \mathrm{H} 1 \mathrm{~N} 1$ pandemic, whereby $5.9 \%$ of patients hospitalized for influenza virus infection had thrombotic vascular events (Bunce et al., 2011).

In addition to mediating cytokine production, endothelial cells may also indirectly control the inflammatory response in the lung during IAV infection via the expression of adhesion molecules, such as E-selectin, P-selectin, ICAM1, and VCAM1, on their apical surface. These adhesion molecules can bind to various leukocytes and mediate their extravasation to the infected lung. The increased expression of E/P-selectin expression on human endothelial cells following exposure to H5N1 (Perrone et al., 2008) may therefore account for the increased inflammatory response (and lung lesions) associated with this virus. In sum, whilst human endothelial cells are not infected with IAV, endothelial cells still play an important role in the pathogenesis of IAV in humans.

\section{CONCLUSIONS AND FUTURE DIRECTIONS}

Endothelial cells play important but distinct roles in the pathogenesis of IAV in wild birds, poultry and humans. Whilst endothelial cells are infected by HPAI viruses in chickens and swans, in humans they are more important in driving and controlling the inflammatory response in the lung. It is important to note that endothelial cells in both chickens and swans may also influence the inflammatory response to IAV. It has already been suggested that the overwhelming endothelial tropism of $\mathrm{H} 5 \mathrm{~N} 1$ viruses in poultry may disrupt the innate immune response (Suzuki et al., 2009). However, the details of this 'disruption' have been hard to elucidate due to the limited availability of reagents to study the avian immune response. This remains a key research priority for the future. In addition, what makes the endothelial cells of chickens and black swans (and not those of other wild bird species and humans) so permissive to $\mathrm{H} 5 \mathrm{~N} 1$ viruses in vivo remains to be determined. It is likely that as research and the availability of reagents for studying avian species continues to grow new roles for endothelial cells in pathogenesis of IAV will be discovered. However, what is clear at present is that endothelial cells contribute to the severity of IAV infections across multiple different species.

\section{ACKNOWLEDGMENTS}

We thank Judith van den Brand and Debby van Riel for the provision of histology sections. Kirsty R. Short is supported by an NHMRC C. J. Martin post-doctoral fellowship (1054081). Thijs Kuiken is supported by European Union FP7 ANTIGONE contract 278976 .

\section{REFERENCES}

Armstrong, S. M., Darwish, I., and Lee, W. L. (2013). Endothelial activation and dysfunction in the pathogenesis of influenza A virus infection. Virulence 4, 6 . doi: 10.4161/viru.25779

Armstrong, S. M., Wang, C., Tigdi, J., Si, X., Dumpit, C., Charles, S., et al. (2012). Influenza infects lung microvascular endothelium leading to microvascular leak: role of apoptosis and claudin-5. PLoS ONE 7:e47323. doi: 10.1371/journal.pone.0047323

Babinska, A., Kedees, M. H., Athar, H., Ahmed, T., Batuman, O., Ehrlich, Y. H., et al. (2002). F11-receptor (F11R/JAM) mediates platelet adhesion to endothelial cells: role in inflammatory thrombosis. Thromb. Haemost. 88, 843-850. doi: $10.1267 /$ th02110843

Becker, W. (1966). The isolation and classification of tern virus: influenza virus A/tern/South Africa/1961. J. Hyg. 64, 309-320. doi: 10.1017/S002217240 0040596

Bertran, K., Dolz, R., Busquets, N., Gamino, V., Vergara-Alert, J., Chaves, A. J., et al. (2013). Pathobiology and transmission of highly and low pathogenic avian influenza viruses in European quail (Coturnix c. coturnix). Vet. Res. 44:23. doi: 10.1186/1297-9716-44-23

Bertran, K., Perez-Ramirez, E., Busquets, N., Dolz, R., Ramis, A., Darji, A., et al. (2011). Pathogenesis and transmissibility of highly (H7N1) and low (H7N9) pathogenic avian influenza virus infection in red-legged partridge (Alectoris rufa). Vet. Res. 42:24. doi: 10.1186/1297-9716-42-24

Bröjer, C., Ågren, E. O., Uhlhorn, H., Bernodt, K., Mörner, T., Jansson, S., et al. (2009). Pathology of natural highly pathogenic avian influenza H5N1 infection in wild tufted ducks (Aythya fuligula). J. Vet. Diagn. Invest. 21, 579-587. doi: 10.1177/104063870902100501

Brown, C., Olander, H., and Senne, D. (1992). A pathogenesis study of highly pathogenic avian influenza virus H5N2 in chickens, using immunohistochemistry. J. Comp. Pathol. 107, 341-348. doi: 10.1016/0021-9975(92)90009-J

Brown, J. D., Stallknecht, D. E., Beck, J. R., Suarez, D. L., and Swayne, D. E. (2006). Susceptibility of North American ducks and gulls to H5N1 highly pathogenic avian influenza viruses. Emerg. Infect. Dis. 12, 1663-1670. doi: 10.3201/eid1211.060652

Brown, J. D., Stallknecht, D. E., and Swayne, D. E. (2008a). Experimental infection of swans and geese with highly pathogenic avian influenza virus (H5N1) of Asian lineage. Emerg. Infect. Dis. 14, 136-142. doi: 10.3201/eid1401. 070740 
Brown, J. D., Stallknecht, D. E., and Swayne, D. E. (2008b). Experimental infections of herring gulls (Larus argentatus) with H5N1 highly pathogenic avian influenza viruses by intranasal inoculation of virus and ingestion of virus-infected chicken meat. Avian Pathol. 37, 393-397. doi: 10.1080/03079450802216595

Bunce, P. E., High, S. M., Nadjafi, M., Stanley, K., Liles, W. C., and Christian, M. D. (2011). Pandemic H1N1 influenza infection and vascular thrombosis. Clin. Infect. Dis. 52, e14-e17. doi: 10.1093/cid/ciq125

Chan, M., Chan, R., Yu, W., Ho, C., Chui, W., Lo, C., et al. (2009). Influenza H5N1 virus infection of polarized human alveolar epithelial cells and lung microvascular endothelial cells. Respir. Res. 10:102. doi: 10.1186/1465-9921-10-102

Daoust, P.-Y., Kibenge, F. S., Fouchier, R. A., Van De Bildt, M. W., Van Riel, D., and Kuiken, T. (2011). Replication of low pathogenic avian influenza virus in naturally infected mallard ducks (Anas platyrhynchos) causes no morphologic lesions. J. Wildl. Dis. 47, 401-409. doi: 10.7589/0090-3558-47.2.401

Ellis, T. M., Bousfield, R. B., Bissett, L. A., Dyrting, K. C., Luk, G. S., Tsim, S. T., et al. (2004). Investigation of outbreaks of highly pathogenic H5N1 avian influenza in waterfowl and wild birds in Hong Kong in late 2002. Avian Pathol. 33, 492-505. doi: 10.1080/03079450400003601

Feldmann, A., Schäfer, M. K.-H., Garten, W., and Klenk, H.-D. (2000). Targeted infection of endothelial cells by avian influenza virus A/FPV/Rostock/34 (H7N1) in chicken embryos. J. Virol. 74, 8018-8027. doi: 10.1128/JVI.74.17.8018-8027.2000

Gorin, A. B., and Stewart, P. A. (1979). Differential permeability of endothelial and epithelial barriers to albumin flux. J. Appl. Physiol. 47, 1315-1324.

Gu, J., Xie, Z., Gao, Z., Liu, J., Korteweg, C., Ye, J., et al. (2007). H5N1 infection of the respiratory tract and beyond: a molecular pathology study. Lancet 370, 1137-1145. doi: 10.1016/S0140-6736(07)61515-3

Hooper, P., and Selleck, P. (2003). Pathology of low and high virulent influenza virus infections. Avian Dis. 47, 134-141.

Ito, T., Kobayashi, Y., Morita, T., Horimoto, T., and Kawaoka, Y. (2002). Virulent influenza A viruses induce apoptosis in chickens. Virus Res. 84, 27-35. doi: 10.1016/S0168-1702(01)00414-2

Jones, Y. L., and Swayne, D. E. (2004). Comparative pathobiology of low and high pathogenicity H7N3 Chilean avian influenza viruses in chickens. Avian Dis. 48, 119-128. doi: 10.1637/7080

Kalthoff, D., Breithaupt, A., Teifke, J. P., Globig, A., Harder, T., Mettenleiter, T. C., et al. (2008). Highly pathogenic avian influenza virus (H5N1) in experimentally infected adult mute swans. Emerg. Infect. Dis. 14, 1267-1270. doi: 10.3201/eid1408.080078

Kuiken, T., Van Den Brand, J., Van Riel, D., Pantin-Jackwood, M., and Swayne, D. (2010). Comparative pathology of select agent influenza a virus infections. Vet. Pathol. 47, 893-914. doi: 10.1177/0300985810378651

Kwon, Y.-K., Joh, S.-J., Kim, M.-C., Sung, H.-W., Lee, Y.-J., Choi, J.-G., et al. (2005). Highly pathogenic avian influenza (H5N1) in the commercial domestic ducks of South Korea. Avian Pathol. 34, 367-370. doi: 10.1080/03079450500181257

Kwon, Y. K., Thomas, C., and Swayne, D. E. (2010). Variability in pathobiology of South Korean H5N1 high-pathogenicity avian influenza virus infection for 5 species of migratory waterfowl. Vet. Pathol. 47, 495-506. doi: $10.1177 / 0300985809359602$

Lee, C. W., Suarez, D. L., Tumpey, T. M., Sung, H. W., Kwon, Y. K., Lee, Y. J., et al. (2005). Characterization of highly pathogenic H5N1 avian influenza A viruses isolated from South Korea. J. Virol. 79, 3692-3702. doi: 10.1128/JVI.79.6.36923702.2005

Londt, B. Z., Nunez, A., Banks, J., Nili, H., Johnson, L. K., and Alexander, D. J. (2008). Pathogenesis of highly pathogenic avian influenza A/turkey/Turkey/1/2005 H5N1 in Pekin ducks (Anas platyrhynchos) infected experimentally. Avian Pathol. 37, 619-627. doi: 10.1080/0307945080 2499126

Muramoto, Y., Ozaki, H., Takada, A., Park, C. H., Sunden, Y., Umemura, T., et al. (2006). Highly pathogenic H5N1 influenza virus causes coagulopathy in chickens. Microbiol. Immunol. 50, 73-81. doi: 10.1111/j.1348-0421.2006.tb03764.x

Mutinelli, F., Capua, I., Terregino, C., and Cattoli, G. (2003). Clinical, gross, and microscopic findings in different avian species naturally infected during the H7N1 low- and high-pathogenicity avian influenza epidemics in Italy during 1999 and 2000. Avian Dis. 47, 844-848. doi: 10.1637/0005-2086-47.s3.844

Nakamura, K., Imada, T., Imai, K., Yamamoto, Y., Tanimura, N., Yamada, M., et al. (2008). Pathology of specific-pathogen-free chickens inoculated with H5N1 avian influenza viruses isolated in Japan in 2004. Avian Dis. 52, 8-13. doi: 10.1637/8027-060607-Reg
Nakatani, H., Nakamura, K., Yamamoto, Y., Yamada, M., and Yamamoto, Y. (2005). Epidemiology, pathology, and immunohistochemistry of layer hens naturally affected with H5N1 highly pathogenic avian influenza in Japan. Avian Dis. 49, 436-441. doi: 10.1637/7304-110504R1.1

Neufeld, J. L., Embury-Hyatt, C., Berhane, Y., Manning, L., Ganske, S., and Pasick, J. (2009). Pathology of highly pathogenic avian influenza virus (H5N1) infection in Canada geese (Branta canadensis): preliminary studies. Vet. Pathol. 46, 966-970. doi: 10.1354/vp.08-VP-0168-E-FL

Noymer, A., and Garenne, M. (2000). The 1918 influenza epidemic's effects on sex differentials in mortality in the United States. Popul. Dev. Rev. 26, 565-581. doi: 10.1111/j.1728-4457.2000.00565.x

Ocaña-Macchi, M., Bel, M., Guzylack-Piriou, L., Ruggli, N., Liniger, M., McCullough, K. C., et al. (2009). Hemagglutinin-dependent tropism of H5N1 avian influenza virus for human endothelial cells. J. Virol. 83, 12947-12955. doi: 10.1128/JVI.00468-09

Ogiwara, H., Yasui, F., Munekata, K., Takagi-Kamiya, A., Munakata, T., Nomura, N., et al. (2014). Histopathological evaluation of the diversity of cells susceptible to H5N1 virulent avian influenza virus. Am. J. Pathol. 184, 171-183. doi: 10.1016/j.ajpath.2013.10.004

Pantin-Jackwood, M. J., and Swayne, D. E. (2007). Pathobiology of Asian highly pathogenic avian influenza H5N1 virus infections in ducks. Avian Dis. 51, 250-259. doi: 10.1637/7710-090606R.1

Pantin-Jackwood, M., and Swayne, D. (2009). Pathogenesis and pathobiology of avian influenza virus infection in birds. Rev. Sci. Tech. 28, 113-136.

Pasick, J., Berhane, Y., Embury-Hyatt, C., Copps, J., Kehler, H., Handel, K., et al. (2007). Susceptibility of Canada Geese (Branta canadensis) to highly pathogenic avian influenza virus (H5N1). Emerg. Infect. Dis. 13, 1821-1827. doi: 10.3201/eid1312.070502

Perkins, L. E., and Swayne, D. E. (2001). Pathobiology of A/chicken/Hong Kong/220/97 (H5N1) avian influenza virus in seven gallinaceous species. Vet. Pathol. 38, 149-164. doi: 10.1354/vp.38-2-149

Perkins, L. E., and Swayne, D. E. (2002a). Pathogenicity of a Hong Kongorigin $\mathrm{H} 5 \mathrm{~N} 1$ highly pathogenic avian influenza virus for emus, geese, ducks, and pigeons. Avian Dis. 46, 53-63. doi: 10.1637/0005-2086(2002)046[0053: POAHKO]2.0.CO;2

Perkins, L. E., and Swayne, D. E. (2002b). Susceptibility of laughing gulls (Larus atricilla) to $\mathrm{H} 5 \mathrm{~N} 1$ and $\mathrm{H} 5 \mathrm{~N} 3$ highly pathogenic avian influenza viruses. Avian Dis. 46, 877-885. doi: 10.1637/0005-2086(2002)046[0877:SOLGLA] 2.0.CO;2

Perkins, L. E., and Swayne, D. E. (2003). Comparative susceptibility of selected avian and mammalian species to a Hong Kong-origin H5N1 high-pathogenicity avian influenza virus. Avian Dis. 47, 956-967. doi: 10.1637/0005-208647.s3.956

Perrone, L. A., Plowden, J. K., García-Sastre, A., Katz, J. M., and Tumpey, T. M. (2008). H5N1 and 1918 pandemic influenza virus infection results in early and excessive infiltration of macrophages and neutrophils in the lungs of mice. PLoS Pathog. 4:e1000115. doi: 10.1371/journal.ppat.1000115

Piantadosi, C. A., and Schwartz, D. A. (2004). The acute respiratory distress syndrome. Ann. Intern. Med. 141, 460-470. doi: 10.7326/0003-4819-141-6200409210-00012

Reperant, L. A., Van De Bildt, M. W., Van Amerongen, G., Leijten, L. M., Watson, S., Palser, A., et al. (2012). Marked endotheliotropism of highly pathogenic avian influenza virus $\mathrm{H} 5 \mathrm{~N} 1$ following intestinal inoculation in cats. J. Virol. 86, 1158-1165. doi: 10.1128/JVI.06375-11

Rimmelzwaan, G. F., Van Riel, D., Baars, M., Bestebroer, T. M., Van Amerongen, G., Fouchier, R. A., et al. (2006). Influenza A virus (H5N1) infection in cats causes systemic disease with potential novel routes of virus spread within and between hosts. Am. J. Pathol. 168, 176-183. doi: 10.2353/ajpath.2006.050466

Schat, K. A., Bingham, J., Butler, J. M., Chen, L.-M., Lowther, S., Crowley, T. M., et al. (2012). Role of position 627 of PB2 and the multibasic cleavage site of the hemagglutinin in the virulence of $\mathrm{H} 5 \mathrm{~N} 1$ avian influenza virus in chickens and ducks. PLoS ONE 7:e30960. doi: 10.1371/journal.pone.0030960

Shieh, W.-J., Blau, D. M., Denison, A. M., Deleon-Carnes, M., Adem, P., Bhatnagar, J., et al. (2010). 2009 pandemic influenza A (H1N1): pathology and pathogenesis of 100 fatal cases in the United States. Am. J. Pathol. 177, 166-175. doi: 10.2353/ajpath.2010.100115

Shinya, K., Ebina, M., Yamada, S., Ono, M., Kasai, N., and Kawaoka, Y. (2006). Avian flu: influenza virus receptors in the human airway. Nature 440, 435-436. doi: $10.1038 / 440435 a$ 
Suarez, D. L., Perdue, M. L., Cox, N., Rowe, T., Bender, C., Huang, J., et al. (1998). Comparisons of highly virulent $\mathrm{H} 5 \mathrm{~N} 1$ influenza A viruses isolated from humans and chickens from Hong Kong. J. Virol. 72, 6678-6688.

Suzuki, K., Okada, H., Itoh, T., Tada, T., Mase, M., Nakamura, K., et al. (2009). Association of increased pathogenicity of Asian H5N1 highly pathogenic avian influenza viruses in chickens with highly efficient viral replication accompanied by early destruction of innate immune responses. J. Virol. 83, 7475-7486. doi: 10.1128/JVI.01434-08

Swayne, D. E. (2007). Understanding the complex pathobiology of high pathogenicity avian influenza viruses in birds. Avian Dis. 51, 242-249. doi: 10.1637/7763-110706-REGR.1

Teifke, J. P., Klopfleisch, R., Globig, A., Starick, E., Hoffmann, B., Wolf, P. U., et al. (2007). Pathology of natural infections by H5N1 highly pathogenic avian influenza virus in mute (Cygnus olor) and whooper (Cygnus cygnus) swans. Vet. Pathol. 44, 137-143. doi: 10.1354/vp.44-2-137

Teijaro, J. R., Walsh, K. B., Cahalan, S., Fremgen, D. M., Roberts, E., Scott, F., et al. (2011). Endothelial cells are central orchestrators of cytokine amplification during influenza virus infection. Cell 146, 980-991. doi: 10.1016/j.cell.2011. 08.015

van Riel, D., Den Bakker, M. A., Leijten, L. M., Chutinimitkul, S., Munster, V. J., De Wit, E., et al. (2010). Seasonal and pandemic human influenza viruses attach better to human upper respiratory tract epithelium than avian influenza viruses. Am. J. Pathol. 176, 1614-1618. doi: 10.2353/ajpath.2010.090949

van Riel, D., Munster, V., De Wit, E., Rimmelzwaan, G., Fouchier, R., Osterhaus, A., et al. (2007a). Human and avian influenza viruses target different cells in the lower respiratory tract of humans and other mammals. Am. J. Pathol. 171, 1215. doi: 10.2353/ajpath.2007.070248

van Riel, D., Munster, V. J., De Wit, E., Rimmelzwaan, G. F., Fouchier, R. A., Osterhaus, A. D., et al. (2006). H5N1 virus attachment to lower respiratory tract. Science 312, 399-399. doi: 10.1126/science.1125548

van Riel, D., Munster, V. J., De Wit, E., Rimmelzwaan, G. F., Fouchier, R. A., Osterhaus, A. D., et al. (2007b). Human and avian influenza viruses target different cells in the lower respiratory tract of humans and other mammals. Am. J. Pathol. 171, 1215-1223. doi: 10.2353/ajpath.2007.070248

van Riel, D., van den Brand, J., Munster, V., Besteboer, T., Fouchier, R., Osterhaus, A., et al. (2009). Pathology and virus distribution in chickens naturally infected with highly pathogenic avian influenza A virus (H7N7) during the 2003 outbreak in The Netherlands. Vet. Pathol. Online 46, 971-976. doi: 10.1354/vp.08VP-0215-K-BC

Wang, S., Le, T. Q., Kurihara, N., Chida, J., Cisse, Y., Yano, M., et al. (2010). Influenza Virus-cytokine-protease cycle in the pathogenesis of vascular hyperpermeability in severe influenza. J. Infect. Dis. 202, 991-1001. doi: 10.1086/656044

Webster, R. G., Bean, W. J., Gorman, O. T., Chambers, T. M., and Kawaoka, Y. (1992). Evolution and ecology of influenza A viruses. Microbiol. Rev. 56, $152-179$.

Wibawa, H., Bingham, J., Nuradji, H., Lowther, S., Payne, J., Harper, J., et al. (2013). The pathobiology of two Indonesian H5N1 avian influenza viruses representing different clade 2.1 sublineages in chickens and ducks. Comp. Immunol. Microbiol. Infect. Dis. 36, 175-191. doi: 10.1016/j.cimid.2012.12.001

Yamamoto, Y., Nakamura, K., Kitagawa, K., Ikenaga, N., Yamada, M., Mase, M., et al. (2007). Severe nonpurulent encephalitis with mortality and feather lesions in call ducks (Anas platyrhyncha var. domestica) inoculated intravenously with H5N1 highly pathogenic avian influenza virus. Avian Dis. 51, 52-57. doi: 10.1637/0005-2086(2007)051[0052:SNEWMA]2.0.CO;2

Zeng, H., Pappas, C., Belser, J. A., Houser, K. V., Zhong, W., Wadford, D. A., et al. (2012). Human pulmonary microvascular endothelial cells support productive replication of highly pathogenic avian influenza viruses: possible involvement in the pathogenesis of human H5N1 virus infection. J. Virol. 86, 667-678. doi: 10.1128/JVI.06348-11

Zhou, J. Y., Shen, H. G., Chen, H. X., Tong, G. Z., Liao, M., Yang, H. C., et al. (2006). Characterization of a highly pathogenic H5N1 influenza virus derived from bar-headed geese in China. J. Gen. Virol. 87, 1823-1833. doi: 10.1099/vir.0.81800-0

Conflict of Interest Statement: The authors declare that the research was conducted in the absence of any commercial or financial relationships that could be construed as a potential conflict of interest.

Received: 15 October 2014; paper pending published: 03 November 2014; accepted: 12 November 2014; published online: 02 December 2014.

Citation: Short KR, Veldhuis Kroeze EJB, Reperant LA, RichardM and Kuiken T (2014) Influenza virus and endothelial cells: a species specific relationship. Front. Microbiol. 5:653. doi: 10.3389/fmicb.2014.00653

This article was submitted to Virology, a section of the journal Frontiers in Microbiology.

Copyright (c) 2014 Short, Veldhuis Kroeze, Reperant, Richard and Kuiken. This is an open-access article distributed under the terms of the Creative Commons Attribution License (CC BY). The use, distribution or reproduction in other forums is permitted, provided the original author(s) or licensor are credited and that the original publication in this journal is cited, in accordance with accepted academic practice. No use, distribution or reproduction is permitted which does not comply with these terms. 